\section{Recuperación de la estética modernista en la ilustración contemporánea y su vinculación con el diseño de moda}

Recovery of Modernist Aesthetics in Contemporary Illustration and its Relationship with Fashion Design

Yulia Iskakova

\section{Comparación de épocas}

¿Vivimos un modernismo del siglo XXI?

El diseño de moda, la ilustración y el arte contemporáneo están viviendo un renacer de tendencias parecidas a las que marcaron la frontera entre los siglos XIX y XX: la era del Modernismo en el Arte.

También, como entonces, vemos un contraste entre el boom del desarrollo tecnológico y las corrientes ecológicas de acercamiento a la naturaleza: el "eco arte», el "eco fashion", el "eco diseño", el "slow fashion"... todos tienen en común un interés protector hacia la naturaleza y el planeta tanto desde el punto de vista de la de la producción industrial como del consumo.

"El arte ambiental o arte ecológico (ecoarte) ha evolucionado desde los movimientos del "earth-art" y el "land-art" de los años 60 y principios de los 70, y se ha visto muy influido por la obra de Joseph Beuys y sus acciones medioambientales "en defensa de la naturaleza"definidas por él mismo como esculturas sociales. El arte ecológico ahora proporciona un contexto para la educación ambiental, y se logra mano a mano con las comunidades. Los Ecoartistas tratan de acceder y convertirse en defensores de las comunidades, trabajando como co-alumnos y también como co-creadores. Su trabajo es colaborativo y da apoyo tanto al ecosistema natural como al social".

En el diseño de moda de estas corrientes se utilizan materiales reciclables: ropa hecha con papel de periódico o con materiales de plástico como vasos, cubiertos, botellas, creando nuevas obras muy vanguardistas ("newspaper couture" o "recycled fashion" o "paper dress", "moda sostenible"(Fig.1)).

También se presta mucha atención al proceso de elaboración de la prenda para que respete al máximo a la naturaleza utilizando fibras y tintes naturales sin química.

Por otra parte podemos observar las tendencias en el arte y el diseño de Moda donde la naturaleza se utiliza como fuente de inspiración para mostrar la belleza del mundo que nos rodea. De hecho, el producto de la moda se convierte en muchas ocasiones en una obra de arte por sí misma: hay esculturas y prendas de vestir hechas con materiales como hierbas, flores, ramas y raíces de árboles

\section{El precedente}

La Revolución Industrial, proceso histórico que se gesta en Inglaterra a fines del siglo XVIII y comienzos del XIX, marca el comienzo de la fabricación en serie y tiene como punto de referencia la Gran Exposición Internacional de Londres de 1851 que era la primera exposición donde presentaron los productos industriales.

De estos ejemplares expuestos se hizo una profunda crítica en su época que denunciaban la falta de calidad y de adecuación al uso de estos productos industriales.

La no aceptación de la mecanización en el arte se expresó en una nueva corriente basada en las ideas estéticas de John Ruskin (historiador y critico de Arte) y William Morris (artesano, impresor, diseñador, escritor,
Palabras clave: llustració moda, Naturaleza y Arte, Fuentes de inspiración Key words: Illustration, Modern Style, Fashion Design, Nature in Art, Sources of inspiration veloping at a breakneck pace. Every day many new discoveries are made in all fields of science and art. We think that we have gone far ahead compared with the past century. People tend to It is surp But they say, everything new is well forgotten old similar trends in fashion design and illustration in particular that marked the last century, the era of modernity. Also, as then, we see the need for people to seek inspiration in nature, flowers, butterflies, insects. Currently we are seeing these trends in all branches of design and art. In this work we will be analyzing this interconnection on examples of works of illustrators, photographer and fashion designers. 
poeta, activista y político), que presentó el ideal del arte medieval. Este último, junto con artistas del movimiento prerrafaelista, trató de descubri la belleza del trabajo artesanal que se desarrollaba en talleres frente a la producción que se llevaba a cabo en las nuevas zonas industriales.

A raíz de este movimiento, en 1880 en los trabajos de varios artistas se empieza a desarrollar un estilo totalmente nuevo con nuevas lineas estilísticas que llevarán al nacimiento de la corriente artística llamada "Modernismo" en España, también conocida como "Art Nouveau" en Francia, "Jugendstil" en Alemania, "Sezession" en Austria, "Modern Style" en Inglaterra, "Style sapin" en Suiza, "Nieuwe Kunst" en los Países Bajos, "Liberty o Floreale" en Italia, "Tiffany" en Estados Unidos y "Modern" en Rusia.

En los distintos países comienzan a surgir asociaciones artísticas que trabajan en un nuevo estilo : "Arts and Crafts" en Londres (1888) gobernadas por William Morris; la Glasgow School gobernada por Charles Rennie Mackintosh; "La Secesión de Viena" (Vereinigung Bildender Künstler Österreich)(1903) en Austria gobernada por Gustav Klimt; "L'École de Nancy" en Francia; "Mir iskusstva" (Mundo del Arte) (1890) en Rusia.

La época del Modernismo es el principio del diseño y de la profesión de diseñador tal y como la conocemos ahora.

Así, a finales del XIX y principios del siglo XX, el desarrollo de la tecnología (la litografía, la fotografía) y el nuevo estilo de arte (moderno) llevó a la realización de nuevos medios de expresión en el cartel artístico, por un lado, y la aparición de revistas de arte necesarias para la promoción del Arte Nuevo, por el otro.

La necesidad de nuevos medios de comunicación e impresión en la segunda mitad del siglo XIX ha obligado a las impresoras a mejorar la tecnología y prestar atención al diseño de los productos. Por ejemplo, en París, el tipógrafo Jules Chéret fue uno de los primeros en darse cuenta de las posibilidades de la impresión litográfica a cuatro colores para los carteles artísticos. Esta tecnología obligó a los artistas a hacer trabajos muy decorativos y gráficos trabajando con las manchas de colores y contornos muy afilados, creando un lenguaje de ilustración totalmente nuevo (Henri de Toulouse-Lautrec, Alfonse Mucha y otros.)

El diseño gráfico se erige como una actividad artística independiente a partir de su funcionalidad del sistema de signos y la estética. El término "diseño gráfico" lo utilizó por primera vez el diseñador estadounidense William E. Dvidzhings en 1922

Ejemplos evidentes de este nuevo estilo de comunicación y diseño los podemos encontrar en las revistas: "The Studio", "Revue Blanshet", "Jugend", "Mir Iskusstva", "Die Form", "Equilibrio", "The Golden Fleece", etc., donde tanto forma como contenido crearon un producto único en el ámbito de los medios de comunicación.

\section{Mitologia y simbolismo del Modernismo}

La época del Modernismo encontraba inspiración en las formas de la naturaleza. Sus valores filosóficos y estéticos eran la ruptura con la tradición, la innovación permanente, y la búsqueda de nuevos estilos en el Arte y nuevos valores en la vida.

En definitiva, una nueva nueva plataforma ideológica, una revolución espiritual una nueva conciencia y una nueva concepción de la vida. En sus fundamentos encontramos la psicología introspectiva de Bergson y Lossky; la fenomenología de Husserl, el psicoanálisis de Sigmund Freud y Carl Jung; el existencialismo de Kierkegaard, Heidegger, Karl Jaspers, Berdyaev y otros.

Y además, a raíz de estos cambios radicales el Modernismo empieza florecer no solamente en la pintura, escultura y arquitectura, sino también en las artes aplicadas o decorativas, en las artes gráficas y en el diseño de mobiliario, forja, joyería, cristalería, cerámica, lámparas y todo tipo de objetos de la vida cotidiana, incluido el mobiliario urbano y el diseño de moda.

Una característica común para el Modernismo europeo es la idealización y la estilización del patrimonio medieval. El interés en lo fantástico como una manifestación del pensamiento mitológico, se convirtió en un rasgo característico de la época.

La feminidad en el Modernismo

En un lugar especial en la iconografía de la época encontramos la belleza y la imagen femenina.

La Feminidad se elevó a la altura de un principio sagrado de la vida. Hadas, diosas, princesas... en las obras de artistas e ilustradores surge toda una lista de títulos poéticos que hacen hincapié en la imagen femenina.

Así, el joyero francés René Lalique glorificó a la naturaleza en la oyería, extendiendo su repertorio para incluir aspectos nuevos no tan convencionales (como libélulas y hierbas) inspirados en sus encuentros con el arte japonés.

El Modernismo tenia interés hacia las flores y trataba a cada de ellas como personajes individuales. Las favoritas de los artistas fueron sin duda orquídeas, tulipanes, lirios y iris. En 1856, el pintor francés, grabador y ceramista F. Brakmon vio por primera vez la xilografía japonesa de color de K. Hokusai en la tienda en París. Muy pronto estas xilografías extraordinarias inspiraron a muchos artistas franceses.

Uno de los más significativos de la época en esta temática fue Alfonse Mucha, pintor y artista decorativo checo. Se hizo famoso después de hacer su primer cartel litográfico para la actriz Sarah Bernhardt y su Théâtre de la Renaissance en 1894

Durante de los siguientes años se hizo muy popular como autor de etiquetas de champan, galletas y otros productos de consumo, y como diseñador de joyas, interiores, y objetos de artes aplicadas como alfombras o cortinas.

Los periódicos parisinos escribieron sobre un nuevo fenómeno: «La mujer de Mucha" que se reproducía por miles de copias en los carteles, postales, las cartas de juego etc. Los gabinetes y las salas de los mejores restaurantes, así como los tocadores de las damas se adornaban 
con calendarios y grabados del maestro. Sus series gráficas "Estaciones", "Flores", "Árboles", "Estrellas", y "Piedras preciosas" siguen siendo replicadas en carteles hasta la actualidad.

El centro de composición de los trabajos de Alfonse Mucha son las mujeres jóvenes y hermosas rodeadas de flores como una imagen simbólica de las fuerzas de la naturaleza. Hay una comparación de las mujeres con la belleza de las flores. La mujer como una expresión de la vida, como el inicio y la continuación de una nueva era y un símbolo de la belleza. En 1898 Mucha creó una serie especial de pinturas llamada "Flores" que incluía lirios, claveles y rosas.

En nuestro tiempo sigue la influencia de las mujeres de Alfonso Mucha, como podemos ver en la serie de fotografías de la británica Kirsty Mitchell llamada "Wonderland" inspirada en los recuerdos infantiles de los cuentos que le leía su madre. En estas fotografías revivimos imágenes de la era Modernista en la que la heroína es la mujer vestida con ropa y sombreros tejidos con flores y hojas. Este proyecto ganó el Premio Internacional de Fotografía en 2014 y fue publicado en numerosos periódicos y revistas.

Algo similar podemos observar en los modelos de Alexander McQueen de la Primavera/Verano 2007 . Posiblemente el diseño de vestidos en las fotografías de Kirsty Mitchell se parecen tanto a vestidos de Alexander McQueen porque ella también estudió diseño de moda y trabajó en casa de Alexander McQueen.

Otro autor de la época del modernismo es Gustav Klimt que

representa la Secesión Vienesa. Las composiciones dinámicas de sus trabajos contraponen el juego de los fondos decorativos con la belleza pintoresca de la imagen medio desnuda de la mujer. En las obras de Klimt la mujer es símbolo de erotismo.

El contraste de los fondos coloridos con la belleza del cuerpo la podemos ver en los trabajos del fotógrafo Zhang Jingna para la colección primavera/verano 2015 de Phuong My y Gucci Resort 2013 donde vemos a la mujer rodeada de flores.

La mujer rodeada de flores es un tema muy popular en las campañas de diversas marcas de ropa.

Por ejemplo la marca Stella McCartney en su colección para la Primavera/Nerano de 2012 es un excelente ejemplo de la mezcla de épocas con el fondo floral de color y el modelo en blanco y negro combinando lo modernista con lo contemporáneo.

Otro artista de la época del Modernismo es el ruso León Bakst (pintor, ilustrador de libros y decorador teatral) una de las figuras más prominentes de "Mir Iskusstva" ( "Mundo del Arte", el modernismo de Rusia). Sus trabajos se exponen por primera vez en 1998 dentro de la "exposición de artistas rusos" organizada por Diaghilev. Desde 1907 Bakst vivió en Paris y trabajó en escenografías que fueron una verdadera revolución. El hizo los decorados para las tragedias griegas y en 1908 entró en la historia como el autor de la escenografía y el vestuario para los Ballets Rusos de Sergei Diaghilev: "Cleopatra" en 1909,

\section{Bibliografía}

C. RYDER, Material Culture: Socia Change, Culture, Fashion and Textiles in Europe, In Woodhead Publishing Series in Textiles, edited by Rose Sinclair, Woodhead Publishing 2015, Pages 563-603, Textiles and Fashion, ISBN 9781845699314 TON, DAVID ELIWAND, Fairio ality: The Fashion Collection from the House of Ellwand, Candlewick: First Edition edition (November 1, 2002). 130 pages ISBN 978-0763614133 Eskilson Stephen J. Graphic Design A History. Second edition. London, 2012. GONTAR, CYBELE. "Art Nouveau": In Heilbrunn Timeline of Art Histor New York: The Metropolitan Museum of Art, 2000-. htp./MWw hd_artn.htm (October 2006) SHOE FLEUR: A Footwear Fantasy September, Michel Tcherevkoff, Fe rrucio Ferragamo, Welcome Books; Slp edition (September 4, 2007) ISBN-10: 1599620367

PHILIP COOKE, The resilience of sustainability, creativity and social justice from the arts \&amp "eco-painting" City Cudern day ciety, Availabl online 2 A pril 2015, ISSN 1877-9166

RAICU, L., D. MARIN, AND C. RADULESCU. "DESIGN SOURCES AND ARTISTIC TRENDS. "University" Politehnica" of Bucharest Scientific Bulletin, Series D: Mechanical Engineering 68.4 (2006): 51-80 SANJUKTA POOKULANGARA, ARLESA SHEPHARD, Slow fashio mor pert. Understanding consustudy, Journal of Retailing and Consumer Services, Volume 20, Issue 2. March 2013, Pages 200-206 TORRENT, ROSALÍA Y MARÍN JOAN M. Historia del diseño industrial, Madrid, Cátedra 2009, Madrid.

\section{Enlaces}

Alexander McQueen Spring/Summer 2007. hctp./MWw.vogue.co.uk to-wear/alexander-mcqueen fecha de consulta 05.04.2015 BIZUU. http://www.bizuu.pl http://www.zeberka.pl//art/bizuu-kolekcja-wiosna-lato-2013-foto-21958
"Scheherazade" en 1910 "Carnaval" en 1910, "Narciso" 1911 "Dafnis y Cloe" 1912.

En sus ilustraciones Bakst utiliza composiciones muy dinámicas con telas florales.

Una de las fuentes de formación del nuevo diseño de moda en esta época era el teatro que al mismo tiempo se convirtió en inspiración y en un medio de propaganda. En este área Bakst fue un referente clave.

El mismo dinamismo de composición y el juego de las telas estampadas lo podemos encontrar en la campaña de diciembre de 2007 para Vogue Italia del fotógrafo Steven Meisel.

\section{La imagen de la mujer como hada de flores}

La era del cambio de siglos que conocemos como Modernismo estuvo marcada por una inusual atención al folclore por parte de todo tipo de artistas. En la literatura rusa y europea esta tendencia se refleja en la popularidad de las leyendas y los cuentos de hadas que se extiende a las obras teatrales y musicales.

Las imágenes de las hadas y los elfos proliferan en la época del modernismo, especialmente en las joyas. Los joyeros de esta época nos dejaron un patrimonio de piezas impresionantes con imágenes míticas de mujeres-hadas, mujeres- libélulas, mujeres mariposas... Encontramos ejemplos maravillosos en los trabajos de René Lalique joyero francés y uno de los representantes más destacados del Art Nouveau; en los trabajos de Luis Masriera joyero español de Cataluña que tenía un estilo muy personal basado en las influencias de René Lalique; Henri Vever y otros.

Como una continuación de este mundo mágico podemos citar las obra del escritor-ilustrador Ernst Kreidolf (1863-1956) de la época del modernismo de Bern.

Durante varios años vivió en un pequeño pueblo, entre la naturaleza alpina, donde creó un mundo mágico fabuloso y lo pobló de flores humanizas, mariposas, escarabajos y otros insectos ... Todos estas fantásticas metamorfosis las encarnó en ilustraciones de acuarela dentro del estilo Art Nouveau. En 1898 publicó su primer libro de cuentos de hadas. El escritor y artista habló a los niños acerca de un mundo mágico de hadas mágico oculto al ojo humano, donde el dolor y la alegría tenían un sentido así como las cuestiones morales.

La Imagen de hadas de flores aparece ante nosotros en las postales « Flower Girls 1890» de Liebig Trade Company y de Margaret Dulk de Gibson Art Company, 1915 Similares imágenes encontramos en la actualidad en fotógrafos como el vietnamita Duong Quoc Dinh. En sus obras vemos fabulosas imágenes de las mujeres como criaturas míticas, como flores que crecen en la selva.

Pero las imágenes de hadas de flores más conocidas son las de la ilustradora inglesa Cicely Mary Barker que hizo una enorme contribución al desarrollo de esta corriente en sus ocho libros ilustrados, el primero de los cuales se publicó en 1923. (Fig. 15.) La reproducción de estas imágenes en libros y postales continua siendo numerosa hoy en día. 
fecha de consulta 06.03.2015 Barkova, Elfos en las joyas de art nouveau. http:///mith.ru/treasury/ modern/sylf.htm. fecha de consult 02.06.2015 BAKST LEÓN. Visual Art Enciclopedia http://www.wikiart.org/ru/leonbakst/narcisse-1911-1. fecha de CICEIY MARY BARKER. CICELY MARY BARKER. http $v=K$ KIfo-ty3elc http://www.ortakales.com/illustrators/barker.html techa de consulta 05.04.2015 CHANEL, FUTURISTIC FLOWERS FOR CHANEL COUTURE http://www.elle.co.za/futuristic-llowers-chanel-couture/ DOLCE \& GABANA Spring 2014 Botanical Lookbook http://www.swide.com/photo-gallery/look-of-the-day-spring-summ 2014-dolce-and-gabbana-photogallery/2014/01/20/22-24 http://dustyburrito.blogspot. com.es/2014/04/dolce-gabbana-spring-2014-botanical.html fecha de consulta 05.04.2015 Duong Quoc Dinh https://500px.com/DuongQuoc Ernst Kreidolf

http://www.kreidolf.ch/de/ http://50watts.com/The-DreamGarden http://forum.vgd.ru/614/36665/270 $\mathrm{htm}$ ?IB2XPnewforum_=15816b73k f7970c0p15m2lin7. fecha de consul 02.06.2015 ELLWAND HARDCOVER. http:// www.fairie-ality.com,
consulta 05.04.2015

FRANZ GRABE FLOWER COUTU RE http://www.franzgrabe.co.za/ flower_mannequins.html\#bbottom fecha de consulta 02.06.2015 GRACE CIAO http://www.graceciao. com/ https://graceillustrates. wordpress com/ fecha de consulta 05.04.2015 GUCCI RESORT 2013. http://Www vogue.com/tashion-week/862637/ gucci-resort-2013
05.03.2015

KIRSTY MITCHELL. http///licc.us/en/ zoom. php?eid=2-16923-14 http://kirstymitchellphotogra phy.com/2015/01/16/wonder land-wins-second-award-publi-
Por otra parte tenemos que señalar que en las ilustraciones de Cicely vemos no solamente ilustraciones sino también los diseños de vestidos fabulosos. También tenemos que destacar que este detalle es un vínculo directo con el diseño de moda. La moda siempre era reflejo de la sociedad. Por el vestido se podrían deducir muchas cosas como la clase social, el gusto personal y la pertenencia al país y la nacionalidad. Por todo esto la ilustradora antes de hacer su trabajo tenia que imaginar qué vestido podría tener un hada y además cómo eran las hadas de las distintas flores. Cada una de ellas tenía un vestido inspirado en la formas y colores de la misma flor. Desde este punto de vista podemos concluir que este libro no era solamente un abecedario de hadas de flores sino el abecedario del aprendizaje del diseño de moda.

En la siguiente serie de ejemplos de campañas de marcas de Moda vemos una interesante combinación de fotografías sobre fondo de las ilustraciones artísticas de gran tamaño.

Hay una combinación de la ilustración y de la moda con la fotografía donde el centro de la composición es la mujer frágil que parece un Hada paseando entre flores. La misma inspiración que en las ilustraciones de Cicely Mary Barker.

Podemos observar más ejemplos en las fotografías de la colección de Red Valentín 2014 de la Nueva York fashion show, en la campaña de BIZUU de Primavera/Nerano 2013, y en Dolce \& Gabbana

Primavera/Verano 2014. En la campaña de Dolce \& Gabbana, vemos lirios y iris, unas de las flores favoritas de la época del modernismo.

En gran medida el interés en el tema de las flores y las mariposas e insectos en la época del Modernismo había surgido también por causa del interés en la cultura asiática y especialmente la cultura japonesa donde este simbolismo ocupa un papel dominante en el arte y la filosofía. Actualmente estamos viendo la técnica que combina los pétalos de flores y hojas de plantas con el dibujo artístico, justo en los trabajos de los ilustradores de Singapur y Malasia.

En las ilustraciones de moda de Grace Ciao, de Singapur, los diseños de los vestidos nos recuerdan las hadas de flores del Modernismo con una diferencia y es que para la creación de los mismos se habían utilizados hojas y pétalos de flores.

Lim Lizmy Zhi Wei, también de Singapur, y Tang Chiew Ling de Malasia, hacen collages combinando plantas vivas con el dibujo artístico. Estos objetos de la naturaleza, pétalos de flores y hojas complementados por la línea artística y combinados crean interesantes ilustraciones de moda.

Otro ejemplo de combinación del diseño, la fotografía y la ilustración lo podemos ver en en el libro "Fairie Ality-Fashion Collection from the House of Ellwand Hardcover" del fotógrafo Ellwand Hardcover, donde vemos unas asombrosas composiciones del herbolario, pétalos de flores secas y plumas de aves que se nos presentan en forma de vestidos para de hadas y elfos.

En las fotografías de MichelTchetverkoff en su proyecto "Shoe Fleur" el autor crea los accesorios para hadas: zapatos y bolsos fantásticos dise- shed-vogue-international-press/ http://vimeo.com/115575289. fech de consulta 06.03.2015 LIM LIZMY ZHI WEI. http://lovelimzy.blogspot.com.es/p/about.htm http://alternopolis.com/talento-inst gramero-lim-zhi-wei/

MICHEL TCHEREVKOFF. http:// www.tcherevkoff.com/

fetp./Mww.shoefleur.com/ MARGARET DULK. https:/ postcardmuseum. wordpress. com/2011/02/24/dulk-flower-birthday-girls/

https://www.cardcow.com/205713/ birthday-greeting-flowers-plants-tantasy/ fecha de consulta 06.03.2015 TANG CHIEW LING. https://www. behance. net/tangchiewling https://www.behance.net/gaSummer-2015 fechang-My-Spring06.03.2015

Ruta Europea del Modernismo

http://www.artnouveau.eu/es/index. php. fecha de consulta 06.03.2015 STELLA MCCARTNEY Campaign for Spring/Summer 2012 http://www.magnifiermag. com/2012/02/07/stella-mccartney-campaign-for-springsum-

echa de consulta 06.03.2015 $R G$, diseñadora de

http://eccoeco.blogspot.com es/2011/09/indie-designer-mila-ate06.05.2015

Valentino, Red Valentine 2014. hitp://fashionstep.ee/2013/09/ ed-valentino-2014/

http://www.vogue.co.uk/fashion/ spring-summer-2014/ready-to-wear 06.03.2015

Zhang Jing

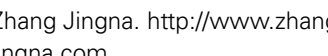

fecha de consulta 06.03.2015 nados a partir de pétalos de flores y hojas de plantas vivas. Como autor describe su proyecto: "Shoe Fleur es acerca de los pensamientos e ideas que proceden de un lugar imposible de encontrar en mi mente donde los colores, formas y fantasías se convierten en imágenes ...

La estética, los colores, y la estructura de las flores y de la naturaleza influyen incluso al diseño de los desfiles de moda aparte del diseño de los vestidos.

Por ejemplo, en el desfile de moda de Chanel de la Primavera 2015, el 28 de enero en Paris Grand Palais, destacó el tema floral de toda colección. Al principio del desfile crecieron por toda la sala flores y plantas robóticas. Como dice el diseñador, este mundo futurista lo vió en sueños y lo tuvo que recrear para este desfile. Es algo romántico, mágico, mítico, un mundo fantástico de hadas donde las mismas modeos parecen hadas de flores en sus vestidos no menos fantásticos que la escenografía del desfile.

Las flores en el diseño de moda es un tema muy popular a lo largo de la historia y en la actualidad. Cada día más podemos observar nuevos diseños magníficos inspirados por naturaleza. ¿Qué es esto? Las mismas tendencias que en el modernismo, llevar nuestros pensamientos y la imaginación a los orígenes del ser humano, hacia nuestra Tierra, nuestra Madre, nuestra Mujer mas bella.

Analizando y comparando dos épocas hemos visto las tendencias florales del Modernismo en las ilustraciones y en el diseño de moda actuales.

Tenemos que aprender ver el mundo mágico de la naturaleza que nos rodea para descubrir que la creación y la imaginación no tienen límites. Tenemos que abrir nuestros ojos, mentes y corazones para encontrar en las cosas que a primera vista parecen simples unas fuentes inagotables de Inspiración.

Y lo que nos puede ayudar muchísimo en este viaje es una mirada hacia atrás, a la experiencia, la vida, los pensamientos y las magníficas creaciones de artistas de tiempos pasados.

\section{Julia Iskakova}

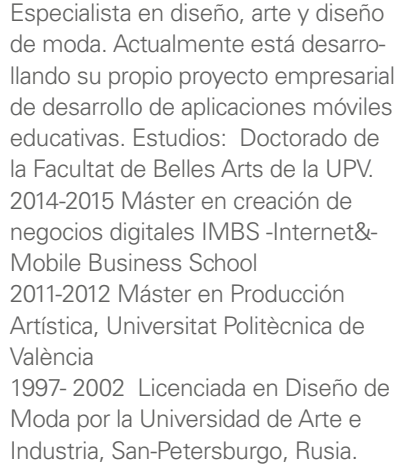

Especialsta en diseno, ante y diseño opio proyecto empresaria de desarrollo de aplicaciones móviles a Facultat de Belles Arts de la UPV. negocios digitales IMBS -Internet\&Mobile Business School Artística, Universitat Politécnica

Moda por la Universidad de Arte

ndustria, San-Petersburgo, Rusi 